\title{
Selective flotation of phosphorus-bearing ores
}

\author{
Abdalla Elbendari ${ }^{1}$, Aleksandr Aleksandrov ${ }^{2}$, Nadezhda Nikolaeva $^{3 *}$ and Anastasiya \\ Afanasova $^{3 \dagger}$ \\ ${ }^{1}$ Central Metallurgical Research and Development Institute (CMRDI), 11668 Cairo, Egypt; \\ ${ }^{2}$ Mining Institute FEB RAS, 51 Turgenev st., Khabarovsk, 680000, Russia; \\ ${ }^{3}$ Federal State Budgetary Educational Institution of Higher Education «Saint Petersburg Mining \\ University», 199106 St. Petersburg, Russia
}

\begin{abstract}
This paper presents the results of the beneficiation of a phosphorus-bearing mineral through selective flotation process. The chemical examination showed that the sample contain a low content of $\mathrm{P}_{2} \mathrm{O}_{5}$ $12.5 \%$ and significant amounts of rare earth elements (REE), \%: yttrium 0.01 , lanthanum - 0.06 , cerium - 0.09 , neodymium - 0.03 . The particle size distribution of the sample was performed, and each separated fraction was chemically analyzed. A detailed examination of the mineralog ical characteristics was conducted using automated mineral liberation analyzer (MLA). It has been shown that the apatite particles are mostly liberated in all fraction sizes. The maximum percentage of apatite polymineral aggregate was recorded in the grain size of $-0.5+0.2 \mathrm{~mm}$, mainly with nepheline and pyroxenes. The maximum percentage of apatite binary aggregate was noted in the grain size of $-0.16+0.071$ and $-0.071+$ $0.045 \mathrm{~mm}$. Based on the obtained results, the size of the flotation feed was predetermined, which allowing the complete liberation of phosphorusbearing mineral (apatite) and avoiding over-grinding of the ore.
\end{abstract}

Key words: selective flotation, selective disintegration, automated mineralogical analysis, apatite, REE.

\section{Introduction}

Phosphorus-bearing minerals are widely used not only as raw materials in the production of fertilizers, but also as a promising source for the extraction of rare earth elements (REE) $[1,2]$. The most promising approach is the development of methods for the extracting of REE using extractants [3].

Flotation is a well-known process of beneficiation, however, due to the complexity of the process and the variety of factors influencing its efficiency, the issue of improving the flotation performance is vitally important. During the process, various types of reagents are used to change the surface properties of minerals [4]. An urgent demand should not only enhance the flotation, but also other associated operations, such as grinding [5-7]. Simultaneously, the addition of chemical reagents during the grinding process makes it

\footnotetext{
* Corresponding autors: Nikolaeva_nv@pers.spmi.ru

${ }^{\dagger}$ Corresponding autors: Afanasova_av@pers.spmi.ru
} 
possible to increase the selectivity of flotation enrichment due to the continuous positive influence of these reagents on the newly created mineral surface $[8,9]$.

Ore dressing are the most energy-consuming processes. Therefore, the intensification of the grinding processes is a huge duty. An approach to overcome this challenge is a thorough assessment of the mineral liberation size, which avoids over-grinding and consequently reduces the cost of grinding. A promising direction for research in this subject is selective disintegration using modern software to analyze the mineral liberation [10-12]. In this regard, increasing the flotation selectivity of Phosphorus-bearing minerals is very essential.

\section{Materials and methods}

A phosphorus-bearing ore is object of research in this work. Table 1 presented the results of chemical analysis. The sample contains a low content of $\mathrm{P}_{2} \mathrm{O}_{5} \sim 12.5 \%$ and high amounts of $\mathrm{SiO}_{2}$ and $\mathrm{Al}_{2} \mathrm{O}_{3}$.

Table 1. Chemical analysis of the original sample

\begin{tabular}{|c|c|c|c|c|c|c|c|}
\hline Components & $\mathrm{SiO}_{2}$ & $\mathrm{TiO}_{2}$ & $\mathrm{Al}_{2} \mathrm{O}_{3}$ & $\mathrm{Fe}$ & $\mathrm{CaO}$ & $\mathrm{MgO}$ & $\mathrm{MnO}$ \\
\hline$\%$ & 32.50 & 2.20 & 15.52 & 5.45 & 18.28 & 0.92 & 0.16 \\
\hline Components & $\mathrm{K}_{2} \mathrm{O}$ & $\mathrm{Na}_{2} \mathrm{O}$ & $\mathrm{P}_{2} \mathrm{O}_{5}$ & $\mathrm{SO}_{3}$ & $\mathrm{CO}_{2}$ & \multicolumn{2}{|c|}{ LOI $^{*}$} \\
\hline$\%$ & 4.20 & 5.56 & 12.50 & 0.04 & 0.05 & \multicolumn{2}{|c|}{2.62} \\
\hline
\end{tabular}

* LOI - loss on ignition

It also should be noted that the ore naturally has significant amounts of REE and its contents are, \%: yttrium - 0.01, lanthanum - 0.06, cerium - 0.09, neodymium - 0.03.

The flotation tests performed in a pneumatic mechanical flotation machine, with the ability to control the air flow rate and impeller speed.

A mixture of distilled, coniferous crude, and deciduous tall oil was used as collector, each of which was separately saponified before being mixed together and fed into the process, Alkyl benzene sulfonic acid was also added to the mixture as a foaming agent. Grinding was carried out using a ball mill. The analysis of flotation products was carried out on an EDX 8000 X-ray fluorescence analyzer, Shimadzu. The mineralogical analysis was performed by using the automated scanning electron microscope (SEM) mineral liberation Analysis (MLA) [13].

\section{Results and discussion}

The chemical analysis was carried out for each separated size fraction (figure 1). The particle size distribution of the crushed sample $(-0.5 \mathrm{~mm})$ showed that the maximum weight percentage $(33.28 \%)$ was retained in the coarse fraction $-0.5+0.2 \mathrm{~mm}$, significant amount was in the medium size fraction of $(-0.16+0.071$ and $-0.071+0.045 \mathrm{~mm})-22.59$ and $11.39 \%$, respectively. The slime size fraction contains $27.02 \%$ of the ore. Such distribution of the sample, the majority of which was in the coarse fraction and, a significant amount was in the slimes (fine particle) may indicate the presence of both hard and soft minerals in the ore. 


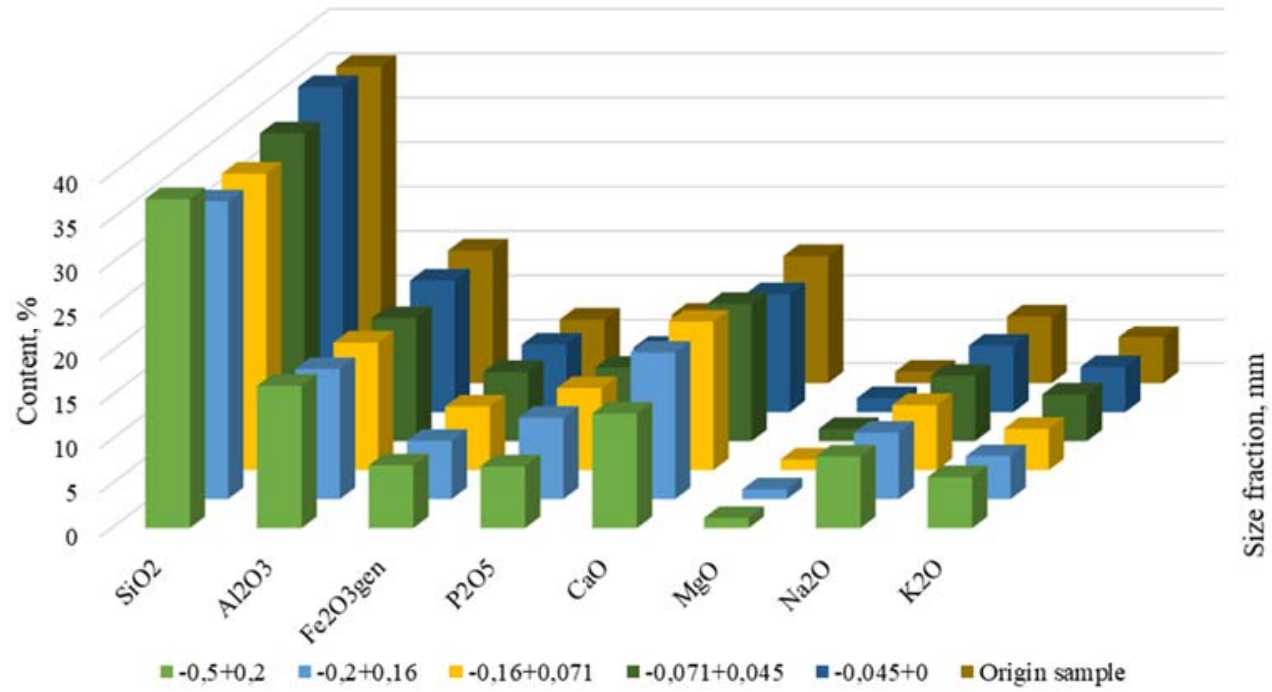

Fig. 1. Content of basic components in phosphorus-bearing ore for each size fraction

Also, the results showed that the content of aluminum, calcium and phosphorus oxides did not show significant variation in the size fractions $\left(\mathrm{Al}_{2} \mathrm{O}_{3}\right.$ - from 14 to $16.06 \%, \mathrm{CaO}-$ from 12.92 to $16.88 \% \mathrm{P}_{2} \mathrm{O}_{5}$ - from 6.96 to $9.27 \%$ ). The content of other components (iron oxides, magnesium, sodium, and potassium) is close and varies in the size fractions within: iron oxide-6.58-7.82\%, magnesium oxide-1.10-1.60\%, sodium oxide-7.35-8.07\%, potassium oxide-4.68-5.75\%, figure 1 .

The results of mineralogical studies using MLA are presented in figure 2.

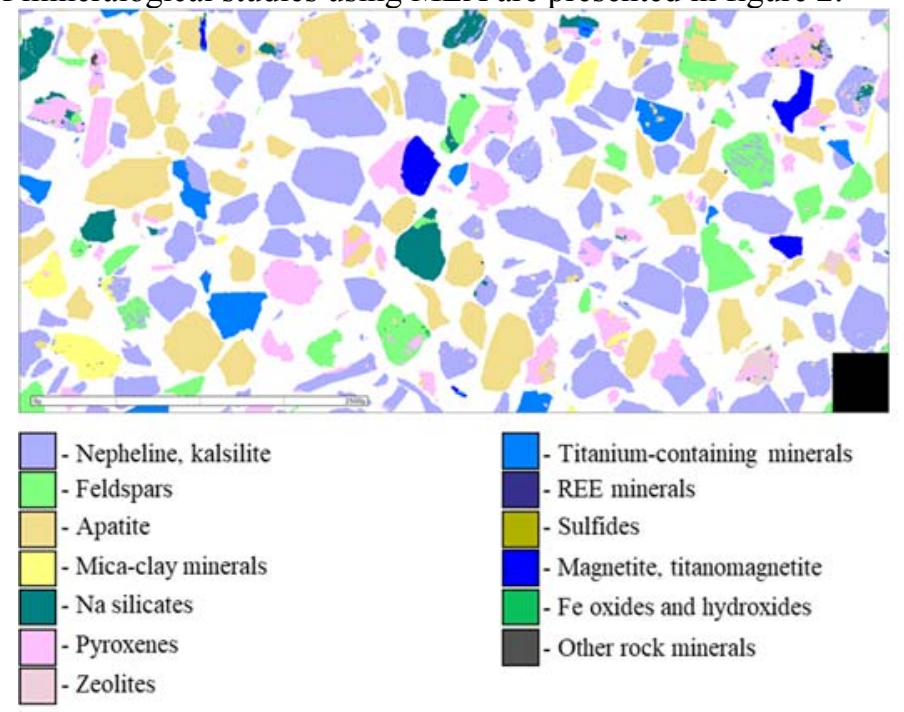

Fig 2. Results of the study of samples of phosphorus-containing ores using automated mineralogical analysis (MLA)

The main minerals of the sample are nepheline, apatite, feldspars and pyroxenes, totaling $81.13 \%$. The ore contains low content ( 1 to $4 \%$ ) of mica, natrolite, cancrinite, sphene, and magnetite. The main phosphorus bearing mineral is apatite, in which $99.92 \%$ of the component is distributed. In rare cases, eshinite, REE and lomonosovite are noted. Strontium- 
bearing minerals of the sample are apatite with percentage of 95.38, and lamprophyllite $(3.77 \%)$. The rest of the strontium $(0.85 \%)$ is found in perovskite and REE minerals.

A detailed analysis of the mineralogical characteristics of apatite was carried out using electron microscopy. Figure 3 shows Apatite aggregates with pyroxenes in their interstitials. apatite grains are in size $0.05-1.0 \mathrm{~mm}$, and predominant between $0.15-0.5 \mathrm{~mm}$. Most of the apatite grains are uniform in structure, but the zonal structure could be observed in some grains.

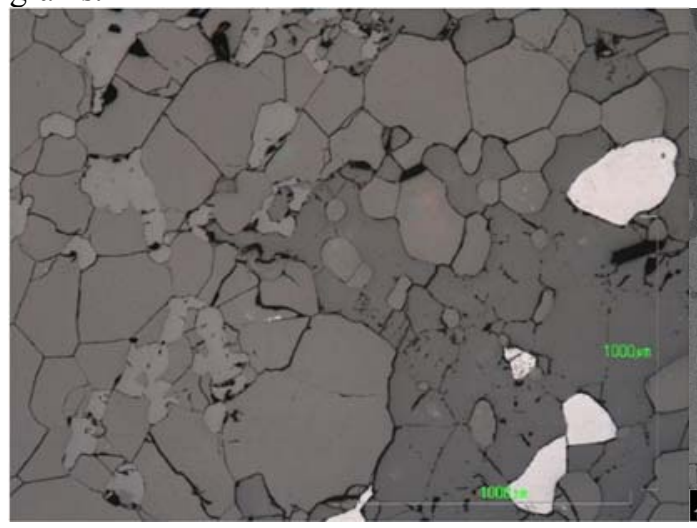

a)

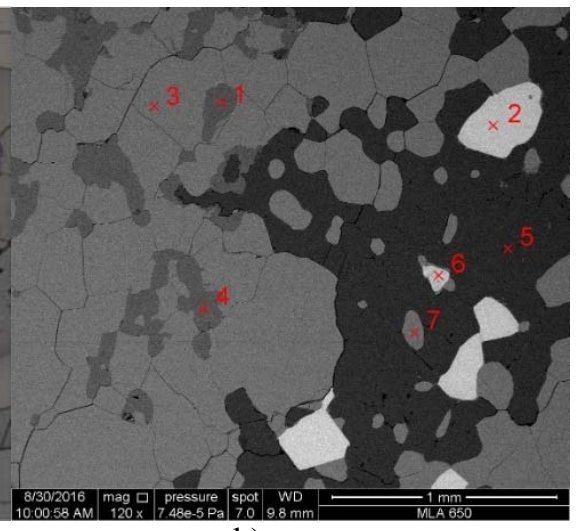

b)

Fig. 3. Apatite aggregates, in the interstices of which pyroxenes develop. The spectra in Fig. b): 1, 4 augite; 2, 6 - titanomagnetite; 3, 7 - apatite; 5 - nepheline. a) - reflected light; b) - in backscattered electrons

A detailed analysis of the mineralogical characteristics of apatite was carried out using electron microscopy. Figure 3 shows Apatite aggregates with pyroxenes in their interstitials. apatite grains are in size $0.05-1.0 \mathrm{~mm}$, and predominant between $0.15-0.5 \mathrm{~mm}$. Most of the apatite grains are uniform in structure, but the zonal structure could be observed in some grains.

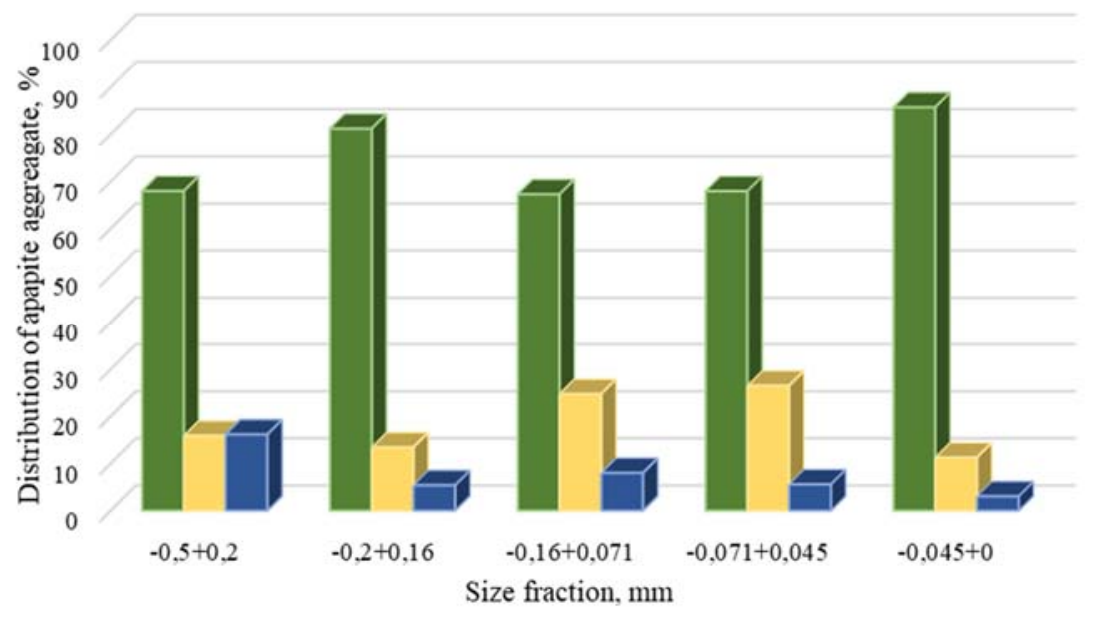

mLiberation particles Bimineral aggregate $=$ Polymineral aggregate

Fig. 4. Distribution of apatite aggregate in phosphorus-bearing ore (MLA)

According to microprobe analysis, apatite belongs to the fluorine-containing type, the average content of fluorine in the mineral is $4.09 \%$; there is a constant admixture of strontium oxide. Analysis of apatite by type of aggregate is shown in figure 4. 
Based on the results, it is established that in all size fractions, the majority of apatite particles (from 70 to $85 \%$ ) are liberated. Moreover, the largest proportion 81.12 and $85.73 \%$ are in size $(-0.2+0.16)$ and $(-0.045+0 \mathrm{~mm})$, respectively. The largest percentage of binary aggregate, making up 24.72 and $26.54 \%$ are in the size fractions $-0.16+0.071 \mathrm{~mm}$ and $0.071+0.045 \mathrm{~mm}$, respectively.

Also, a significant quantity of polymineral and bimineral aggregates in the size fraction of $-0.5+0.2 \mathrm{~mm}$. The smallest percentage of apatite aggregate is observed for the size fraction $-0.045+0 \mathrm{~mm}$. It could be concluded that with a decrease in the size fraction, the liberation of the aggregates will occur, mainly due to bimineral aggregate.

The distribution of apatite in binary aggregate with other prevalent minerals of the sample is shown in figure 5 .

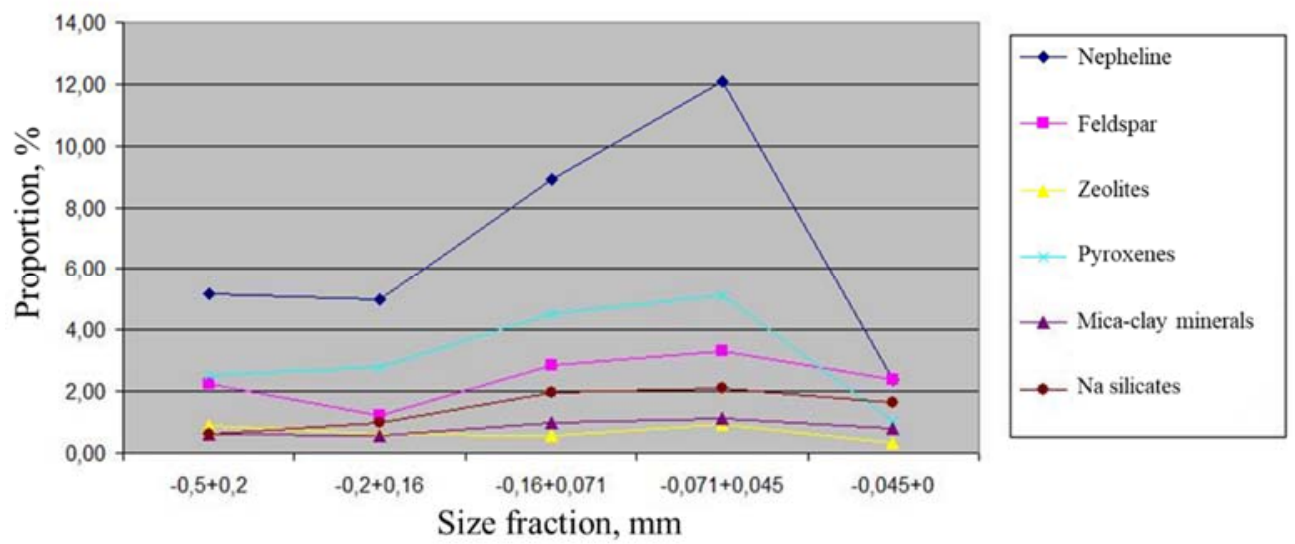

Fig. 5. The proportion of apatite in binary aggregates with other minerals in the classified material of phosphorus-containing ore

It has been shown that in all fine fractions, binary aggregate of apatite with nepheline are observed, with a distinct peak at $(-0.071+0.045 \mathrm{~mm})$ fraction size. In much smaller quantities, there are aggregates of apatite with pyroxenes and feldspar, in which the proportion of apatite in the size $-0.5+0.2 \mathrm{~mm}$ is 2.53 and $2.23 \%$. The highest percentage of binary aggregate of apatite with all the above minerals are obtained for size fractions $-0,16+0,071$ and $0,071+0,045 \mathrm{~mm}$, which determines the particle liberation size of the mineral and, as a consequence, increases the selectivity of the flotation of phosphorus-bearing mineral.

The distribution of the apatite in the composition of polymineral aggregate with other predominant minerals of the sample is shown in figure 6.

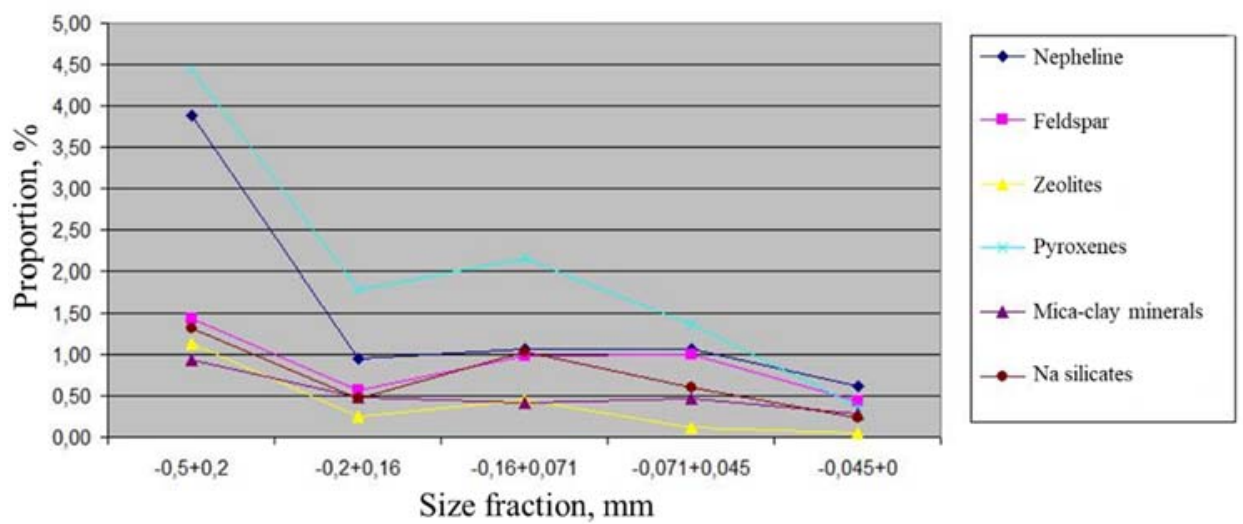


Fig. 6. The proportion of apatite in polymineral aggregates with other minerals in the classified material of phosphorus-containing ore

The largest percentage of polymineral aggregate for apatite is observed in the size fraction $-0.5+0.2 \mathrm{~mm}$, mainly with nepheline and pyroxenes, with a proportion of 3.89 and $4.44 \%$, respectively. Also, the peak of polymineral apatite aggregate with feldspar, nepheline and mica-clay minerals is noted for a particle size of $+0.16+0.071 \mathrm{~mm}$. A significantly smaller number of apatite aggregates is observed in the size of $-0.045+0 \mathrm{~mm}$.

Based on the obtained results, the flotation feed size was determined, which allows for a complete liberation of bimineral and polymineral Apatite aggregates, at the same time avoiding over-grinding of the material, which made it possible to increase the selectivity of flotation separation of phosphorus-bearing ore $-84 \%$ of the class $-0.16 \mathrm{~mm}$.

Figure 7 shows a process flowsheet of phosphorous-bearing ore, including grinding and flotation operations. Flotation process consists of one rougher, two scavenger and three cleaning stages.

Table 2 presents the results of the closed-circuit selective flotation tests.

Table 2. Results of selective flotation of apatite ore in a closed cycle

\begin{tabular}{|l|c|c|c|c|c|c|c|c|c|}
\hline \multirow{2}{*}{ Product } & \multirow{2}{*}{$\begin{array}{c}\text { Yield, } \\
\%\end{array}$} & \multicolumn{5}{|c|}{ Content, \% } & \multicolumn{5}{c|}{ Recovery, \% } \\
\cline { 3 - 10 } & & $\mathrm{Pl}_{2} \mathrm{O}_{3}$ & $\mathrm{SiO}_{2}$ & $\mathrm{Fe}$ & $\mathrm{P}_{2} \mathrm{O}_{5}$ & $\mathrm{Al}_{2} \mathrm{O}_{3}$ & $\mathrm{SiO}_{2}$ & $\mathrm{Fe}$ \\
\hline $\begin{array}{l}\text { Apatite } \\
\text { concentrate }\end{array}$ & 30.64 & 39.26 & 1.02 & 6.28 & 0.78 & 96.23 & 2.01 & 5.92 & 4.39 \\
\hline Tailings & 69.36 & 0.68 & 21.93 & 44.08 & 7.51 & 3.77 & 97.99 & 94.08 & 95.61 \\
\hline Ore & 100.00 & 12.50 & 15.52 & 32.50 & 5.45 & 100.00 & 100.00 & 100.00 & 100.00 \\
\hline
\end{tabular}

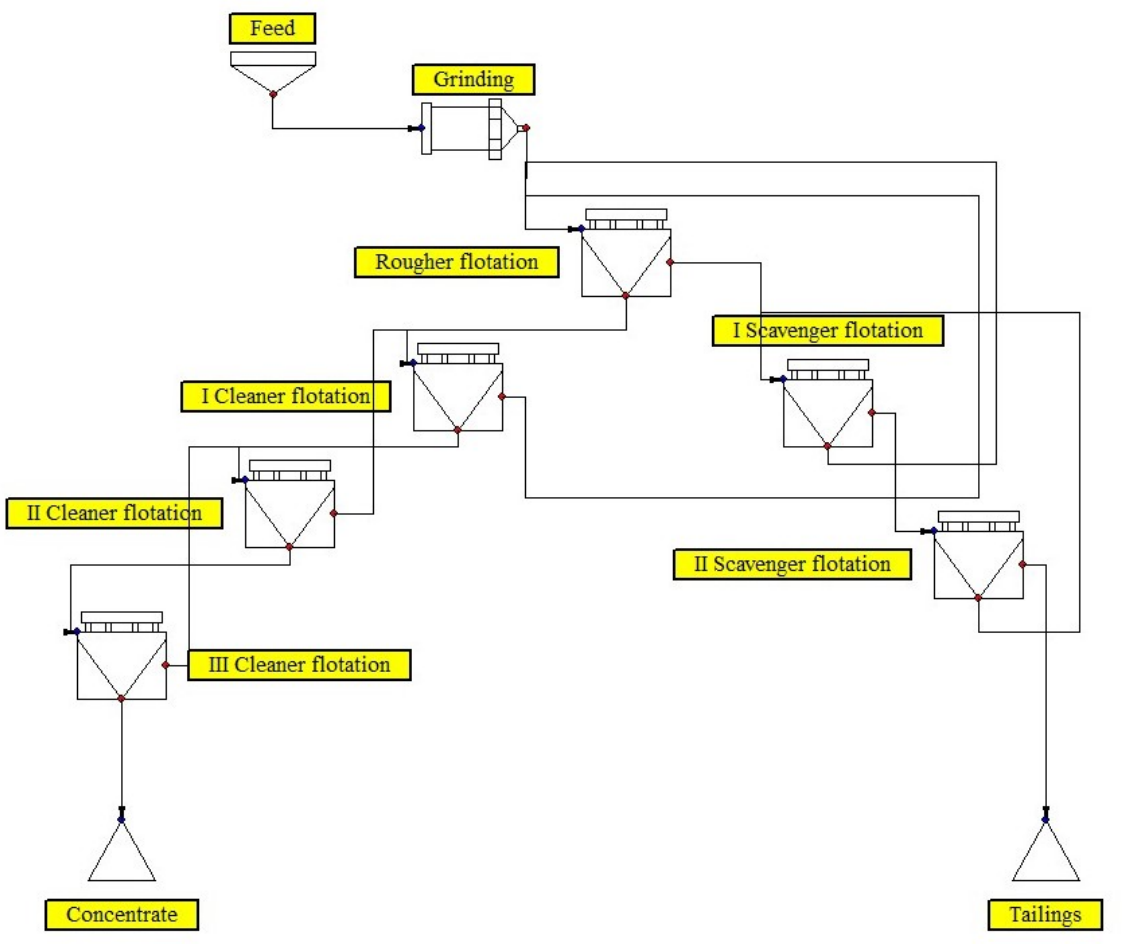

Fig. 7. Scheme of selective flotation for phosphorus-bearing ore

The results of selective flotation beneficiation of phosphorus-bearing ore allow to obtain an increase in both the content and the recovery of $\mathrm{P}_{2} \mathrm{O}_{5}$ in the concentrate. The maximum 
content of $39.26 \% \mathrm{P}_{2} \mathrm{O}_{5}$ with $96.23 \%$ recovery was obtained in the apatite concentrate. An increase in the selectivity of flotation of apatite was obtained by reducing the content of iron, alumina and silicates in the concentrate, which has been successfully accomplished by a complete liberation of the particle during milling based on the findings of a thoroughly mineralogical analysis of the original ore.

\section{Conclusion}

The paper presents the results of a study of selective flotation enrichment of phosphorusbearing ores. Samples of phosphorus-bearing ore with a low content of $\mathrm{P}_{2} \mathrm{O}_{5} 12.5 \%$ were selected for this study. The sample also contains high contents of rare earth elements (REE), $\%$ : yttrium -0.01 , lanthanum -0.06 , cerium -0.09 , neodymium -0.03 . The study of the particle size analysis of $-0.5 \mathrm{~mm}$ crushed sample, showed that the majority of the sample was in the coarse fraction and also, a significant amount was in the slimes (fine particle) may indicate the presence of both hard and soft (easily fractured) minerals in the ore. The results of the mineralogical analysis showed that approximately from 70 to $85 \%$ of apatite particles are liberated in all size fractions. The maximum percentage of apatite polymineral aggregate was observed in the size fraction of $-0.5+0.2 \mathrm{~mm}$, mainly with nepheline and pyroxenes. The maximum percentage of apatite binary aggregate was noted in the size fraction of $0.16+0.071$ and $-0.071+0.045 \mathrm{~mm}$, which determines the liberation size of mineral aggregate and, as a result, increases the selectivity of flotation enrichment of phosphorus-bearing mineral.

Accordingly, the flotation feed size was predetermined, which provides a fully liberated of bimineral and polymineral apatite aggregates, while avoiding over-grinding of the ore, thus increases in the selectivity of flotation enrichment of phosphorus-bearing ore- $84 \%$ of the fraction $-0.16 \mathrm{~mm}$. The content of $39.26 \% \mathrm{P}_{2} \mathrm{O}_{5}$ with $96.23 \%$ recovery was obtained in the apatite concentrate. Increased flotation selectivity of phosphorus-bearing ore was obtained by reducing the content of iron, alumina and silicates in the concentrate, which was achieved by a complete liberation of the aggregates during grinding based on the results obtained from the intimately mineralogical studies of the original ore.

This work was supported by the Russian Science Foundation (project No. 19-17-00096).

\section{References}

1. I. Bagautdinov, A. Kuranov, N. Belyakov \& A. Streshnev, E3S Web of Conferences. 56, 01019 (2018)

2. P. Korchak, E3S Web of Conferences. 56, 02023 (2018)

3. A. Elbendary, T. Aleksandrova, N. Nikolaeva. Journal of Materials Research and Technology. 8(6), 5080-5090 (2019)

4. T. N. Alexandrova, A. O. Romashev, V. V. Kuznetsov. Obogashchenie Rud. 2, 9-14 (2020)

5. T. N. Aleksandrova, A. O. Romashev, V. A. Potemkin, Journal of Applied Engineering Science. 18, 230-237 (2020)

6. X. Gui et al. Powder Technology. 305, 109-116 (2017)

7. A. Opalev et al. International Multidisciplinary Scientific GeoConference: SGEM. 17 (1.1), 1089-1096 (2017)

8. J. Yu et al. Separation and Purification Technology. 190, 45-52 (2018)

9. X. Weng et al. Minerals. 3, 38 (2017)

10. M. Hesse, O. Popov, H. Lieberwirth. Minerals Engineering. 103, 112-126 (2017). 
11. L. Tong et al. Minerals Engineering. 49, 109-115 (2013)

12. T.N. Alexandrova, E.K. Ushakov, A.V. Gorny information-analytical bulletin. 5. 140147 (2020). DOI: 10.25018 / 0236-1493-2020-5-0-140-147.

13. T.N. Alexandrova. Zapiski Gornogo instituta. 220, $568-572$ (2016). DOI 10.18454/PMI.2016.4.568 